\title{
SLC39A6 Positive
}

National Cancer Institute

\section{Source}

National Cancer Institute. SLC39A6 Positive. NCI Thesaurus. Code C141360.

An indication that SLC39A6 expression has been detected in a sample. 